\title{
Research on Reliability of Motor Vehicle
}

\author{
Ivan Palinkaš, Borivoj Šikić, Ljiljana Radovanović, Eleonora Desnica, and Jasmina Pekez
}

\begin{abstract}
This paper presents an reliability analysis of the motor vehicle. The basis for reliability analysis is data obtained by monitoring the vehicle in operation. Based on the failure of some subsystems (components) of the vehicle and the entire vehicle, during operation, it will be determined their characteristics of reliability. Data analysis will be performed for the following parts of the motor vehicle: engine, electrical devices, transmission, braking system and "other" parts. Microsoft Excel will be used as a part of this research for graphical representation of failure rate function $f(t)$, failure function $F(t)$, reliability function $R(t)$ i failure intensity function $\lambda(t)$.
\end{abstract}

Keywords — reliability, motor vehicle, failure

\section{INTRODUCTION}

Reliability is the probability of a certain level of confidence that the system will successfully perform the function for which it was designed without failure and within the defined boundaries of performance, taking into account the time of previous usage of the system, applied in a defined time of task duration [1], [2]. Reliability of the motor vehicle is its ability to perform the required functions in certain conditions for a certain period of time.

Reliability analysis of the motor vehicle, the calculation and graphical display of the failure rate function $\mathrm{f}(\mathrm{t})$, the reliability function $R(t)$ and the failure intensity function $\lambda(t)$, is an extremely important information of the operation of a motor vehicle, which is necessary for making decisions about preventive procedures maintenance to be carried out at certain moments in time, in order to prevent sudden failure, and thus the corresponding downtime and extra expenses. $[3,4,5]$.

Specificity of motor vehicles, as complex systems, is reflected in their structure made up of a number of different elements that are interconnected in complex interactions and that its function, as a rule, do not perform individually but within different functional areas [6].

The ability of the system to perform a function of criteria within the boundaries of permissible deviations is

Manuscript received Dec. 05, 2015. This work was supported in part by the Technical Faculty "Mihajlo Pupin” Zrenjanin.

MSc. Ivan Palinkaš is with Technical Faculty "Mihajlo Pupin” of University of Novi Sad, 23000 Zrenjanin, Serbia.

Major Borivoj Šikić is with Serbian Army Guard, Serbia

Ph.D. Ljiljana Radovanović is with Technical Faculty "Mihajlo Pupin" of University of Novi Sad, 23000 Zrenjanin, Serbia.

Ph.D. Eleonora Desnica is with Technical Faculty "Mihajlo Pupin" of University of Novi Sad, 23000 Zrenjanin, Serbia.

Ph.D. Jasmina Pekez is with Technical Faculty "Mihajlo Pupin” of University of Novi Sad, 23000 Zrenjanin, Serbia. characterized by its state of "work". Condition "in failure" means the inability of the system to, in a mention way, execute the desired function [7].

On a motor vehicle elements or their connections are failing, leading to the failure of higher functional units, and finally to the failure of the system, ie, the whole vehicle. Failure of one element not necessarily presents a system failure, if the element on which the failure occurred has peripheral importance, or if the element is vital, then his failure means the failure of the whole system.

All work and related processes that occur during operation of a motor vehicle lead to the fact that, depending on its age or mileage, failure occurrence of the vehicle or its individual elements is increasing [6].

Causes for failure of technical systems can be [8]:

- Construction - errors of constructor,

- Technology - errors in the part making,

- Exploitation - improper handling or unusual conditions.

In all complex systems, as well as in motor vehicles, the impact of three groups of influence is manifested on system state (or his failures):

- systemic influences, which usually lead to failure in the start of its operations in the initial working period of the system, when, with many of its elements occurs intensive wearing,

- random influences, which are the consequence of factor influence that appear in normal working status of system (stochastic character)

- monotonous - active influence, whose intensity increases with the length of the system working time, such as wear, misalignment, fatigue, aging, corrosion etc.

\section{EXPLOITATION - TECHNICAL SPECIFICATIONS OF MOTOR VEHICLES}

Motor vehicle includes structural components shown in Table 1. It is intended for the transportation of people and materials. The vehicle can move on the roads (payload 2500 $\mathrm{kg}$ ) and wasteland (payload $1500 \mathrm{~kg}$ ). For this purpose it is equipped with a special off-road tires in which the air pressure vary from 0.7 to 3.5 bar.

Vehicle can operate in a temperature range from $-30{ }^{\circ} \mathrm{C}$ to + $40{ }^{\circ} \mathrm{C}$. Permissible draft of vehicles driving in the water is 1 meter deep. Maximum speed of vehicles driving on the road is $90 \mathrm{~km} / \mathrm{h}$ and on the ground $48 \mathrm{~km} / \mathrm{h}$. The vehicle can tow a trailer, gross weight of $1800 \mathrm{~kg}$. 
In first gear in gearbox and in off road transmission in drive distributor, vehicle at full load $(1500 \mathrm{~kg})$ climbs up on $62 \%$ slope, and with a trailer climb up on $44 \%$ sloap (hard pad).

Vehicle is powered by a 4-cylinder, 4-stroke air-cooled diesel engine F4L413 FR with direct fuel injection. Engine power is $81 \mathrm{~kW}(110 \mathrm{hp})$ at $2650[\mathrm{rpm}]$ and transmits it over a dry one-layer connector, fully synchronized transmission with five gears, two-stage transfer case, drive shafts and differentials with forced blocking the front and rear drive bridge at rear wheel drive or optional all-four wheel drive. Transmission is optionally equipped with an additional actuator, which can be used for a variety of associated equipment.

The vehicle frame is composed of two flat longitudinal profiles which are bolted and riveted to transverse support. Front and rear drive axle are hung over linear leaf springs and rubber cushions on the chassis of the vehicle. Front and rear axle are equipped with a shock absorber, and the elasticity of springs and frame contributes to a large extent of adaptability of vehicles on any terrain.

Operating braking system (brake) operates on the principle of hydropneumatic power and has, for the safety, two operating rounds, one of which acts on the front and the other on the rear wheels. If pneumatic part of the braking system fails it can brake only by hydraulic part. Secondary or parking (hand) brake acts on the mechanical-pneumatic principle, and allows the vehicle to stand on the slope of $60 \%$. The vehicle is equipped with the engine brake.

Hydraulic power steering wheel allows the driver full command of the vehicle even on rough terrain. The physical effort required to operate the vehicle is little and it is sufficient for safe driving. In case of failure of part of the hydraulic control system with vehicle can be operated and by mechanical part, but it requires a lot more power.

At the rear part of the vehicle winch is mounted, which is used to pull self, and its traction force is at least $2500 \mathrm{~kg}$. The cabin is open with folding walls and folding fabric roof. Side windows can be removed, and bring down the windshield forward. For better access to the engine compartment can be overturned forward. For heating the cabin a Jugo - Webasto heater is used. Payload body is a steel structure with a concave bottom over its entire length. On the side there are benches for the transportation of people. The sides are rigid, and the rear side has two ladders on the outside. Box is equipped with tarpaulin.

The vehicle is supplied with a spare wheel, spare cans of fuel, maintenance tools, ground-breaking tools and equipment for the winch. In addition, the vehicle has a radio - protection [6].
TABLE I: MOTOR VEHICLE PARTS

\begin{tabular}{cc}
\hline \hline POSITION & NAME \\
\hline 1 & engine \\
2 & drive bridge \\
3 & coupling \\
4 & gearbox \\
5 & drive distributor \\
6 & drive bridge \\
7 & vehicle frame \\
8 & winch \\
9 & air tank \\
10 & fuel tank \\
11 & servo steering wheel \\
\hline \hline
\end{tabular}

Based on previous information, the vehicle can be classified as modern vehicle. This vehicle as vehicle - towing means has very good working characteristics. However, this vehicle has a very complex structure, which may result in an increased failure rate [6].

\section{RESEARCH METHOD}

The aim of the research is to use the results obtained on the characteristics of reliability for the purposes of system maintenance. Had in mind that the maintenance decisions are based on detail study of all features of maintaining system, ie. based on knowledge of all characteristics and features, in particular reliability, or it is decided based on constant insight in current system state, especially on successfulness in performance of working tasks, ie. effect that are accomplished by his work.

Methodology of OPP maintenance is based on knowledge of the reliability characteristics. Using that knowledge it is constantly, during exploitation of technical system, perform forecasts of future failures. Decisions of using procedures for preventive maintenance that must be carried out in certain points in time are made, in order to prevent sudden failure, and by that downtime and additional costs.

One of the most important indicators of reliability of the technical system is a failure intensity function. In a large number of technical systems, the distribution curve of failure intensity is shown in Figure 1 [1].

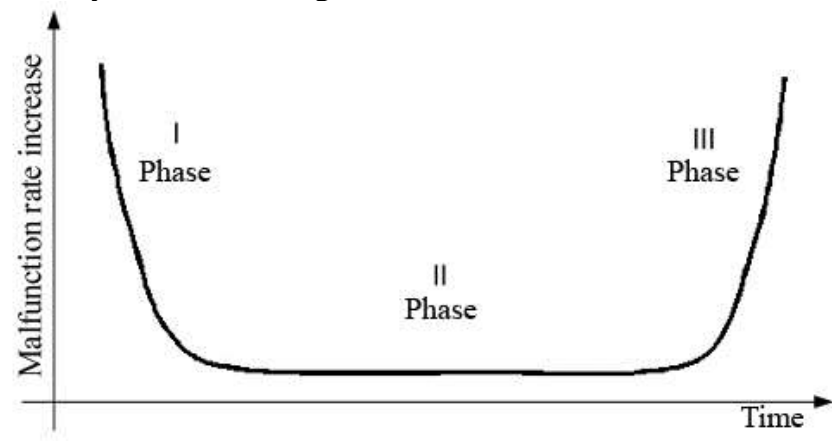

Fig. 1. Distribution of failure intensity during exploitation of system

"Bathtub" curve represents movement of failure intensity in time. It represents three periods (phases) in technical system exploitation:

- Phase I - development (childhood illnesses), a decrease in the failure intensity (infant mortality) 
- Phase II - normal operation, low constant value of failure intensity (Normal life (useful life))

- Phase III - the end of life expectancy, the growth rates of failure. Increased failure intensity due to deterioration of the technical system (End of life wear-out).

In this study, it is assumed that function of failure intensity of motor vehicle have a shape as in Fig.1 after implemented analysis of reliability, based on data acquired by monitoring motor vehicle in exploitation.

To carry out the analysis of reliability of a motor vehicle, using information obtained by monitoring the vehicle in exploitation, it is necessary to define $R(t)$ - function of reliability, $f(t)$ - failure function, $F(t)$ - unreliability function, $\lambda(\mathrm{t})$ - failure intensity function.

The structure of the motor vehicle is a complex technical system, and is defined in Figure 2:

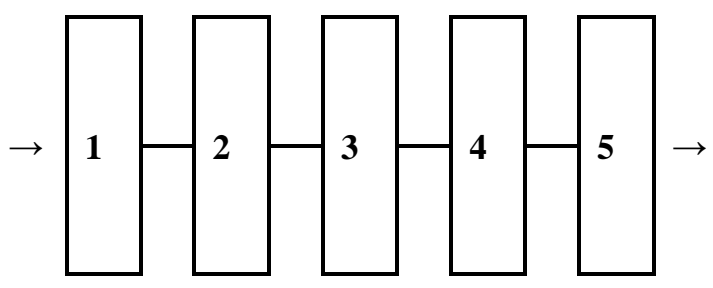

Fig. 2. Motor vehicle structure

As it can be seen in Fig. 2, a motor vehicle is shown by the block diagram with ordinal connection. In addition, each of the elements (blocks) is exact vehicle component, as follows:

1. Transmission $\mathrm{T}$

2. Electrical parts and installations EU

3. Engine $M$

4. The braking device UK

5. Others (cabine, body, steering device, frame, suspension, device for central pressure regulation, wheels and tires) $\mathrm{O}$.

Bearing in mind that the motor vehicle can be presented by ordinal relationship of its parts (elements), means that parts are linked so that failure of any part causes system failure. Reliability of the system with ordinal connected parts is:

$$
R(t)=R_{1}(t) \cdot R_{2}(t) \cdot R_{3}(t) \cdot R_{4}(t) \cdot R_{5}(t)
$$

Reliability is determined by experiment that is conducted over $\mathrm{N}$ equal elements, in same condition, and after time $\mathrm{t}$ in failure it will be $\mathrm{N}_{1}$ elements, and $\mathrm{N}_{2}$ elements will still work:

$$
\begin{aligned}
& N_{2}=N-N_{1} \\
& R(t)=\frac{N-N_{1}(t)}{N}=\frac{N_{2}(t)}{N} \\
& F(t)=\frac{N_{1}(t)}{N}
\end{aligned}
$$

$R(t)+F(t)=\frac{N-N_{1}(t)}{N}+\frac{N_{1}}{N}=1$

The density distribution (density of probability of failure occurrence) is defined as [1]:

$f(t)=\frac{d F(t)}{d t}$

and represents probability of failure occurrence in time [1].

$f(t)=\frac{N_{1}(t)}{\Delta t \cdot N}$

where $\mathrm{t}$ is time interval.

Failure intensity is defined as relation between density function of failure appearance and cumulative density function of working state [1] :

$\lambda(t)=\frac{f(t)}{R(t)}=\frac{N_{2}(t)-N_{2}(t+\Delta t)}{\Delta t \cdot N_{2}(t)}$

\section{EXPERIMENTAL RESEARCH}

The initial criterion for estimating the exploitation reliability of motor vehicles is the frequency of occurrence of the "failure". All other criteria result from the mathematical transformation of this criterion.

Consider a sample of 45 motor vehicles. There are recorded and systematized frequency of occurrence of the "failure" of certain subsystems of the vehicle in function of mileage. It is also included a limited period of use of each vehicle - a systematic overhaul (revision), which ranges from 5 to $70 \times 103$ $\mathrm{km}$.

Based on work orders on audit of motor vehicles the dismissals of some subsystems (components) of the vehicle and for the entire vehicle is systematized, in order to determine their characteristics of reliability.

Failure rate of vehicles by subsystems is shown in Table 2, and the failure rate in intervals of kilometers to overhaul the system is shown in Table 3 and Table 4. Failures of transmission as the most critical subsystems with the largest number of failures, are shown in Table 5.

TABLE II: FAILURE RATE BY VEHICLE SUBSYSTEMS

\begin{tabular}{lccccc}
\hline \hline \multicolumn{1}{c}{ Subsystem } & $\begin{array}{c}\text { Number } \\
\text { of } \\
\text { elements }\end{array}$ & $\begin{array}{c}\text { Number } \\
\text { of } \\
\text { failures }\end{array}$ & $\begin{array}{c}\text { Number } \\
\text { of } \\
\text { failures } \\
\text { by } \\
\text { elements }\end{array}$ & $\%$ & $\begin{array}{c}\text { Critical } \\
\text { RANK }\end{array}$ \\
\hline Transmission T & 6 & 156 & 26 & 23 & 1 \\
$\begin{array}{l}\text { Electrical device } \\
\text { EU }\end{array}$ & 4 & 45 & 11 & 6 & 5 \\
Engine M & 8 & 146 & 19 & 21 & 4 \\
$\begin{array}{l}\text { Breaking device } \\
\text { UK }\end{array}$ & 5 & 121 & 24 & 18 & 2 \\
Other elements O & 10 & 219 & 22 & 32 & 3 \\
TOTAL & $\mathbf{3 3}$ & $\mathbf{6 8 7}$ & $\mathbf{2 1}$ & $\mathbf{1 0 0}$ & \\
FAILURE & & & & & \\
\hline \hline
\end{tabular}


TABLE III: FAILURE RATE IN INTERVALS BY MILEAGE ( 0 - 40000 KM)

\begin{tabular}{ccccccccc}
\hline \hline $\begin{array}{c}\text { Interval } \\
* \mathbf{1 0 0 0} \text { km }\end{array}$ & $\mathbf{0 - 5}$ & $\mathbf{5 - 1 0}$ & $\mathbf{1 0 - 1 5}$ & $\mathbf{1 5 - 2 0}$ & $\mathbf{2 0 - 2 5}$ & $\mathbf{2 5 - 3 0}$ & $\mathbf{3 0 - 3 5}$ & $\mathbf{3 5 - 4 0}$ \\
\hline $\mathbf{T}$ & 35 & 64 & 7 & 19 & 2 & 4 & 3 & 4 \\
$\mathbf{E U}$ & 10 & 23 & 0 & 4 & 1 & 1 & 1 & 0 \\
$\mathbf{M}$ & 39 & 55 & 8 & 9 & 5 & 4 & 2 & 2 \\
$\mathbf{U K}$ & 32 & 44 & 6 & 15 & 2 & 3 & 2 & 2 \\
$\mathbf{O}$ & 53 & 78 & 11 & 29 & 5 & 4 & 5 & 4 \\
$\Sigma$ & 169 & 264 & 32 & 76 & 15 & 16 & 13 & 12 \\
\hline \hline
\end{tabular}

TABLE IV: FAILURE RATE IN INTERVALS BY MILEAGE (40000 - 75000

\begin{tabular}{|c|c|c|c|c|c|c|c|c|}
\hline \multicolumn{9}{|c|}{ KM) } \\
\hline $\begin{array}{c}\text { Interval } \\
* 1000 \text { km }\end{array}$ & $40-45$ & $45-50$ & $50-55$ & $55-60$ & $60-65$ & $65-70$ & $70-75$ & \\
\hline $\mathbf{T}$ & 2 & 3 & 3 & 2 & 1 & 3 & 4 & 156 \\
\hline $\mathbf{E U}$ & 1 & 0 & 1 & 0 & 1 & 1 & 1 & 45 \\
\hline $\mathbf{M}$ & 3 & 3 & 4 & 2 & 2 & 3 & 5 & 146 \\
\hline UK & 3 & 2 & 3 & 1 & 1 & 2 & 3 & 121 \\
\hline o & 7 & 3 & 5 & 4 & 2 & 2 & 7 & 219 \\
\hline$\sum$ & 16 & 11 & 16 & 9 & 7 & 11 & 20 & 687 \\
\hline
\end{tabular}

TABLE V: MOTOR VEHICLE TRANSMISION FAILURE

\begin{tabular}{|c|c|c|c|c|c|c|}
\hline \multicolumn{2}{|c|}{ SUBSYSTEM } & \multicolumn{2}{|c|}{$\begin{array}{l}\text { NUMBER OF } \\
\text { FAILURE }\end{array}$} & \multicolumn{3}{|c|}{$\%$} \\
\hline \multirow{3}{*}{ Coupling } & Disc & 18 & \multirow{3}{*}{57} & 12 & & \multirow{3}{*}{37} \\
\hline & Plate & 20 & & 13 & & \\
\hline & $\begin{array}{c}\text { Coupling } \\
\text { mechanism }\end{array}$ & 19 & & 12 & & \\
\hline Gearshift & & \multicolumn{2}{|c|}{33} & \multicolumn{3}{|c|}{21} \\
\hline Reductor & & \multicolumn{2}{|c|}{34} & \multicolumn{3}{|c|}{22} \\
\hline Differential & & \multicolumn{2}{|c|}{8} & \multicolumn{3}{|c|}{5} \\
\hline Other & & \multicolumn{2}{|c|}{24} & \multicolumn{3}{|c|}{15} \\
\hline TOTAL & & \multicolumn{2}{|c|}{156} & \multicolumn{3}{|c|}{100} \\
\hline
\end{tabular}

\section{PRESENTATION OF RESEARCH RESUlts}

Based on the failure rate of vehicles given in Table 3 and Table 4 an analysis of the reliability characteristics of the following components of a motor vehicle is carried out: engine and transmission, as well as complete vehicle.

For a graphical representation of the failure rate function $\mathrm{f}(\mathrm{t})$, the reliability function $\mathrm{R}(\mathrm{t})$ and the failure intensity function $\lambda$ $(\mathrm{t})$, Microsoft Excel is used.

\section{A. Reliability analysis of motor vehicle engine}

Results shown in Table 6 and Table 7 are obtained based on reliability analysis of a motor vehicle engine. Fig. 3 shows the reliability function $\mathrm{R}(\mathrm{x})$ of the engine, Figure 4 the failure rate function $\mathrm{f}(\mathrm{x})$ of engine, and in Figure 5 the failure intensity function $\lambda(x)$ of engine.
TABLE VI: VALUES R(X), F(X) I $\Lambda$ (X) FOR MOTOR VEHICLE ENGINE IN MILEAGE INTERVALS $(0-30000 \mathrm{KM})$

\begin{tabular}{|c|c|c|c|c|c|c|c|}
\hline $\begin{array}{l}\text { Interval } \\
* 10^{3} \mathbf{~ k m}\end{array}$ & 0 & 5 & 10 & 15 & 20 & 25 & 30 \\
\hline $\mathbf{R}(\mathbf{x})^{*} \mathbf{1 0}^{-2}$ & 100 & 73.2 & 35.6 & 30.1 & 23.9 & 20.5 & 17.8 \\
\hline$f(x)^{*} 10^{-6}$ & 0 & 53.4 & 75.3 & 10.9 & 12.3 & 6.8 & 5.4 \\
\hline$\lambda(\mathrm{x}) * 10^{-6}$ & 0 & & 71.5 & & & 34.2 & \\
\hline
\end{tabular}

TABLE VII: VALUES R(X), F(X) I $\Lambda(\mathrm{X})$ FOR MOTOR VEHICLE ENGINE IN MILEAGE INTERVALS $(35000-75000 \mathrm{KM})$

\begin{tabular}{c|ccc|ccc|ccc}
\hline \hline $\begin{array}{c}\text { Interval } \\
* 10^{3} \mathrm{~km}\end{array}$ & 35 & 40 & 45 & 50 & 55 & 60 & 65 & 70 & 75 \\
\hline $\mathrm{R}(\mathrm{x}) * 10^{-2}$ & 16.4 & 15 & 13 & 10.9 & 8.2 & 6.8 & 5.4 & 3.4 & 0 \\
$\mathrm{f}(\mathrm{x}) * 10^{-6}$ & 2.7 & 2.7 & 4.1 & 4.1 & 5.4 & 2.7 & 2.7 & 4.1 & 6.8 \\
$\lambda(\mathrm{x}) * 10^{-6}$ & & 20.7 & & & 41.3 & & & & \\
\hline \hline
\end{tabular}

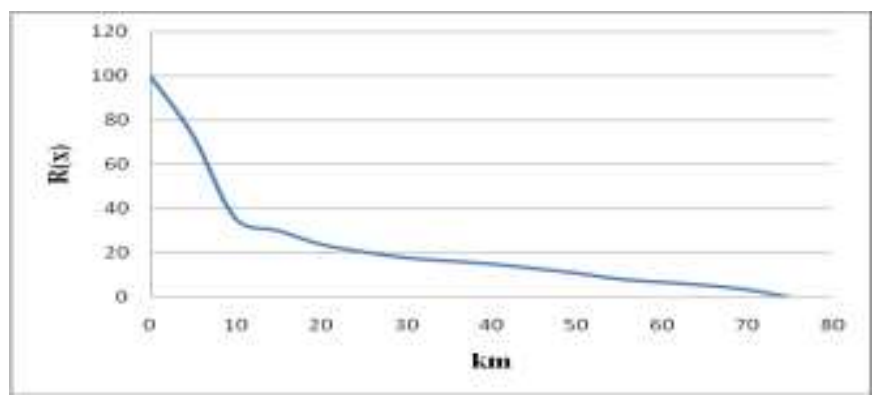

Fig. 3. Reliability function $\mathrm{R}(\mathrm{x})$ of engine

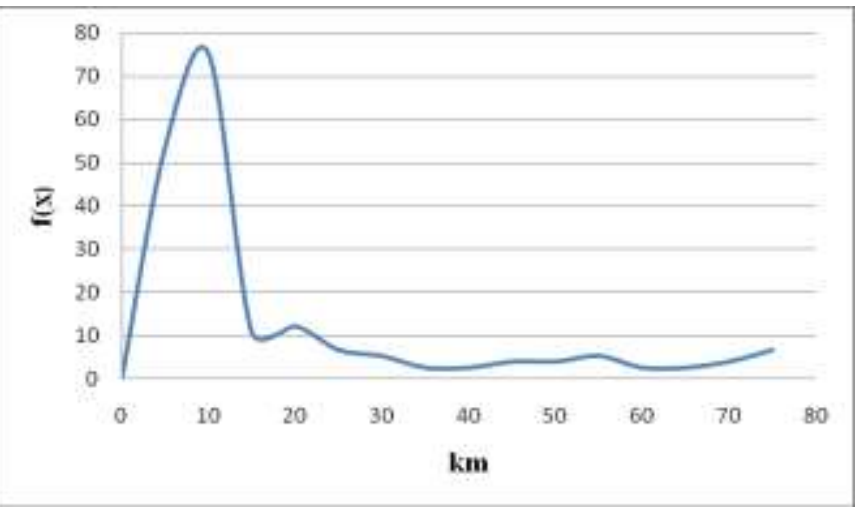

Fig. 4. Failure rate function $\mathrm{f}(\mathrm{x})$ of engine 


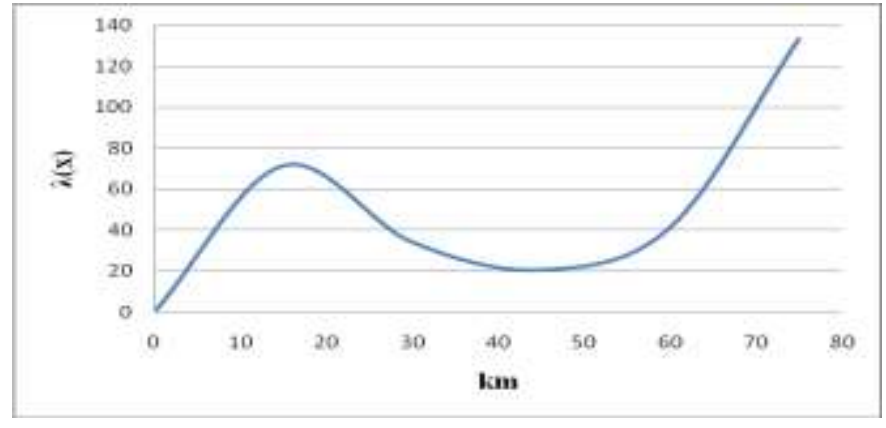

Fig. 5. Failure intensity function $\lambda(x)$ of engine

B. Reliability analysis of motor vehicle transmission system

Based on reliability analysis of the motor vehicle transmission, the following results were obtained, shown in Table 8 and Table 9. In Fig. 6. is the display function of reliability $\mathrm{R}(\mathrm{x})$ of transmission, in Figure 7 the failure rate function $\mathrm{f}(\mathrm{x})$ of transmission, and in Figure 8 the failure intensity function $\lambda(\mathrm{x})$ of transmission.

TABLE VIII: VALUES R(X), F(X) I $\Lambda$ (X) FOR MOTOR VEHICLE TRANSMISSION IN MILEAGE INTERVALS $(0-30000 \mathrm{KM})$

\begin{tabular}{lc|ccc|ccc}
\hline \hline $\begin{array}{l}\text { Interval } \\
* 10^{3} \mathrm{~km}\end{array}$ & 0 & 5 & 10 & 15 & 20 & 25 & 30 \\
\hline $\mathbf{R}(\mathbf{x}) * 10^{-2}$ & 100 & 77.5 & 36.5 & 32 & 19.8 & 18.5 & 16 \\
$\mathbf{f}(\mathbf{x}) * 10^{-6}$ & 0 & 44.8 & 82 & 8.9 & 24.3 & 2.5 & 5.1 \\
$\lambda(\mathbf{x}) * 10^{-6}$ & 0 & & 68.6 & & & & \\
\hline \hline
\end{tabular}

TABLE IX: VALUES R(X), F(X) I $\Lambda$ (X) FOR MOTOR VEHICLE TRANSMISSION IN MILEAGE INTERVALS (35000 - 75000 KM)

\begin{tabular}{|c|c|c|c|c|c|c|c|c|c|}
\hline $\begin{array}{l}\text { Interval } \\
* 10^{3} \mathbf{~ k m}\end{array}$ & 35 & 40 & 45 & 50 & 55 & 60 & 65 & 70 & 75 \\
\hline $\mathbf{R}(\mathbf{x})^{*} 10^{-2}$ & 14.1 & 11.5 & 10.2 & 8.3 & 6.4 & 5.1 & 4.4 & 2.5 & $\mathbf{0}$ \\
\hline$f(x) * 10^{-6}$ & 3.8 & 5.1 & 2.5 & 3.8 & 3.8 & 2.5 & 1.2 & 3.8 & 5.1 \\
\hline$\lambda(\mathrm{x}) * 10^{-6}$ & & 29.2 & & & 50 & & & 133.3 & \\
\hline
\end{tabular}

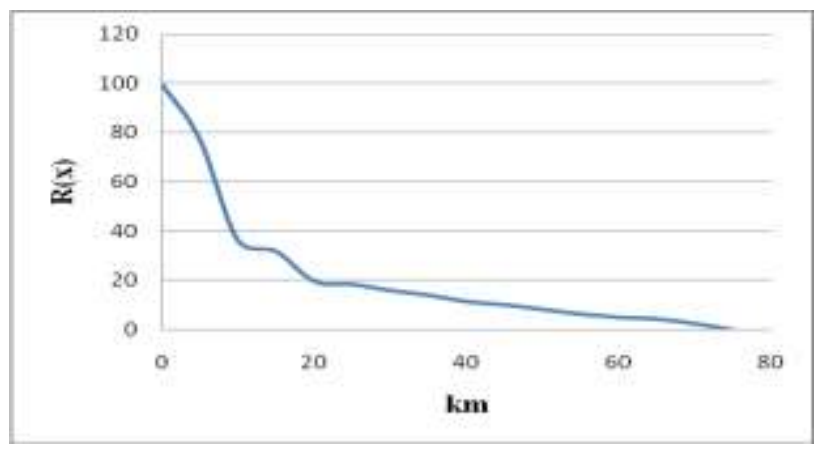

Fig. 6. Reliability function $\mathrm{R}(\mathrm{x})$ of transmission

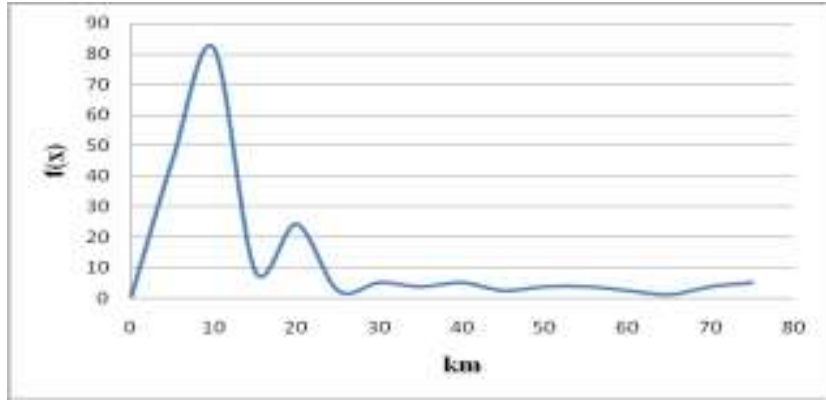

Fig. 7. Failure rate function $\mathrm{f}(\mathrm{x})$ of transmission

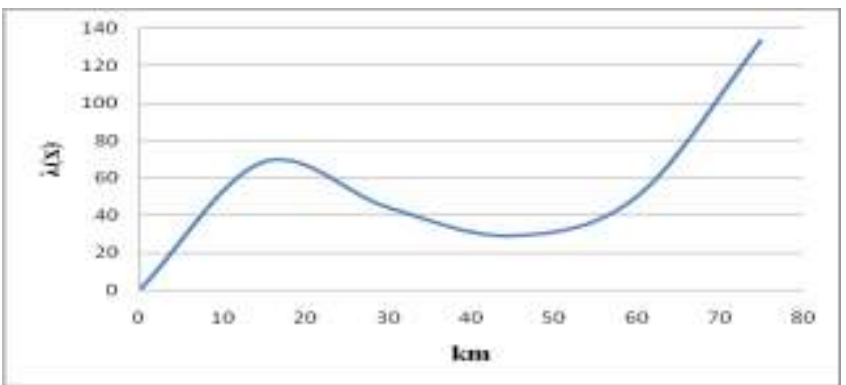

Fig. 8. Failure intensity function $\lambda(\mathrm{x})$ of transmission

\section{Reliability analysis of motor vehicle}

Based on reliability analysis of the motor vehicle, the following results were obtained, shown in Table 10 and Table 11. In Fig. 9. is the display of function of reliability $R(x)$ of motor vehicle, in Figure 10 the failure rate function $\mathrm{f}(\mathrm{x})$ of motor vehicle, and in Figure 11 the failure intensity function $\lambda$ (x) of motor vehicle.

TABLE X: VALUES R(X), $\mathrm{F}(\mathrm{X}) \mathrm{I} \Lambda(\mathrm{X})$ FOR MOTOR VEHICLE IN MILEAGE INTERVALS $(0-30000 \mathrm{KM})$

\begin{tabular}{lc|ccc|ccc}
\hline \hline $\begin{array}{l}\text { Interval } \\
* 10^{3} \mathrm{~km}\end{array}$ & 0 & 5 & 10 & 15 & 20 & 25 & 30 \\
\hline $\mathrm{R}(\mathrm{x}) * 10^{-2}$ & 100 & 75.4 & 36.9 & 32.3 & 21.2 & 19 & 16.7 \\
$\mathrm{f}(\mathrm{x}) * 10^{-6}$ & 0 & 49.1 & 76.8 & 9.3 & 22.1 & 4.3 & 4.6 \\
$\lambda(\mathrm{x}) * 10^{-6}$ & 0 & & 68.2 & & & & \\
\hline \hline
\end{tabular}

TABLE XI: VALUES R(X), F(X) I $\Lambda$ (X) FOR MOTOR VEHICLE IN MILEAGE INTERVALS $(35000-75000 \mathrm{KM})$

\begin{tabular}{c|ccc|ccc|ccc}
\multicolumn{10}{c}{ INTERVALS $(35000-75000 \mathrm{KM})$} \\
\hline \hline $\begin{array}{c}\text { Interval } \\
* 10^{3} \mathrm{~km}\end{array}$ & 35 & 40 & 45 & 50 & 55 & 60 & 65 & 70 & 75 \\
\hline $\mathrm{R}(\mathrm{x}) * 10^{-2}$ & 14.8 & 13.1 & 10.7 & 9.1 & 6.8 & 5.5 & 4.5 & 2.9 & 0 \\
$\mathrm{f}(\mathrm{x}) * 10^{-6}$ & 3.7 & 3.4 & 4.6 & 3.2 & 4.6 & 2.6 & 2 & 3.2 & 5.8 \\
$\lambda(\mathrm{x}) * 10^{-6}$ & & 28.9 & & & 42.8 & & & & \\
\hline
\end{tabular}




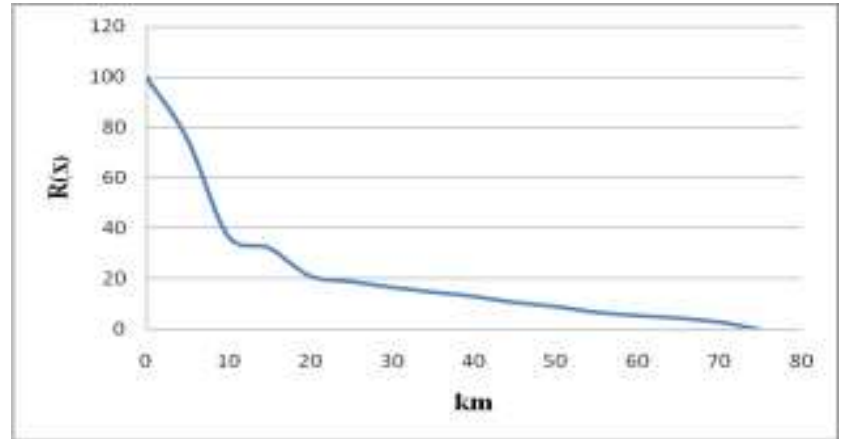

Fig. 9. Reliability function $\mathrm{R}(\mathrm{x})$ of motor vehicle

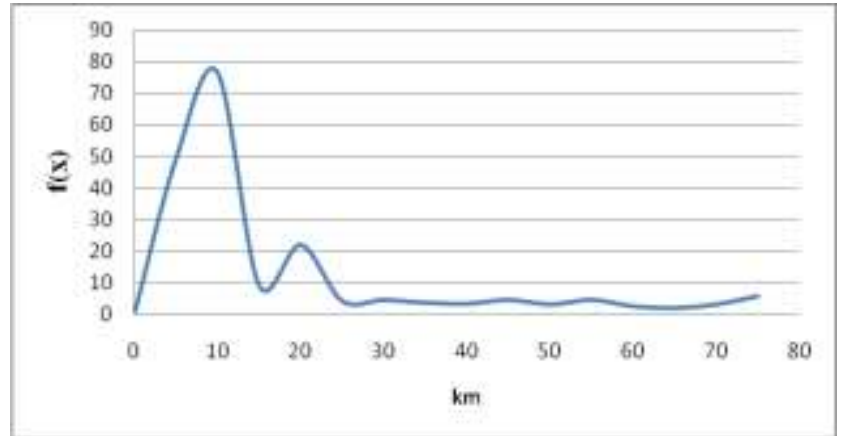

Fig. 10. Failure rate $\mathrm{f}(\mathrm{x})$ of motor vehicle

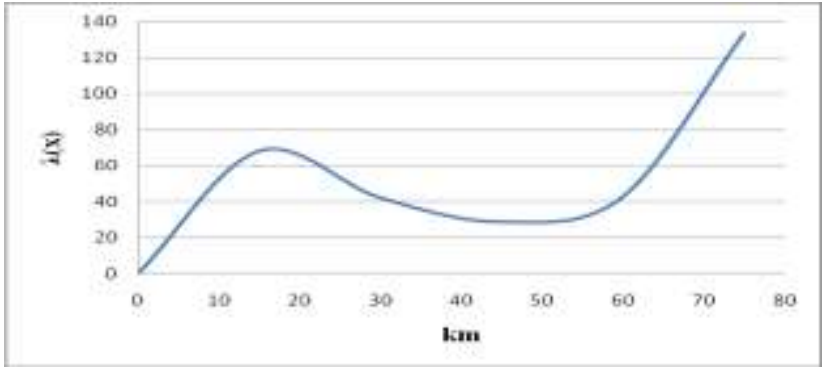

Fig. 11. Failure intensity function $\lambda(\mathrm{x})$ of motor vehicle

\section{CONCLUSION}

Failures of individual components and the vehicle as whole were systematized based on the research conducted on a sample of 45 motor vehicles. The reliability analysis of the vehicle through the calculation and graphical display of the failure rate function $f(t)$, the reliability function $R(t)$ and the failure intensity function $\lambda(t)$ was conducted Microsoft Excel was used in that process.

The failure intensity function of a motor vehicle is shaped like a theoretical curve of the failure intensity distribution of technical system (the "bathtub curve") shown in Fig.1.

It was noted that in the initial period of use of a motor vehicle (Phase 0 to 30,000 km) appears larger number of failures as a result of the initial weakness or missed defects during the manufacture.

Later in the period of "normal" usage (Phase II 30,000.-. $60,000 \mathrm{~km}$ ) failures occur as a result of the stress that goes beyond the built-in resilience of the system. These are so-called "random failures", whose moments of formation cannot be predicted, but it was found that their frequency of occurrence is constant.
In the aging of the technical system there are "late" failures (Phase III over $60,000 \mathrm{~km}$ ) as a result of wear and other failures. This is the time phase when to expect the need for a systemic overhaul (revision) of a motor vehicle.

Based on the obtained characteristics of reliability, it can be forecasted a future state, and predict failures in a motor vehicle. To prevent the occurrence of random failure, and thus the corresponding downtime and additional costs, preventive maintenance procedures should be intensively planned and implemented in the third period-stage operation of a motor vehicle (over $60,000 \mathrm{~km}$ ). Reliability of a motor vehicle as a whole is in the acceptable range.

It was confirmed that most often occurrence of failure are in the elements of transmission, and that a coupling is one of the most critical element by reliability and need for preventive maintenance.

These results are of particular importance for manufacturers and users of a motor vehicle, particularly in terms of development of production and the definition of the maintenance system. The results of this research also can be used to upgrade or modify appropriate normative acts regulating the regime of exploitation, storage and maintenance of motor vehicles [6].

\section{REFERENCES}

[1] Z. Adamovic and Lj. Radovanovic, "Machine reliability", Technical faculty „Mihajlo Pupin“, Zrenjanin, 2008. (in Serbian)

[2] D., Tolmac, S. Prvulovic and $\mathrm{Lj}$. Radovanovic, "Maintenance and management of system reliability ", Machine maintenance, 6 (3): 14- 18, 2006. (in Serbian)

[3] M. Djapić, Lj. Petrovic, E. Desnica et al., "Ensuring reliability of loading and unloading machines during exploitation", 27. May conference of maintenance-Computer integrated maintenace, E -Proceedings Vrnjačka Banja, 2004. (in Serbian)

[4] Lj. Radovanovic and Z. Adamovic, "Reliability analysis of agricultural machines ", Tractors and power machines, 17.(2/3): 93-98, 2012. (in Serbian)

[5] P. O'Connor and A. Kleyner, "Practical reliability engineering", John Wiley \& Sons, UK, 2012.

[6] R. Guberinic and I. Milojevic, "Determening reliability function of motor vehicle as complex system ", Military-technical Gazette 2/09:. 31-45, 2009. (in Serbian)

[7] Armstrong, D., Reliability - Focused Maintenance Materials Management, IDCON, 2008

[8] Aven, T., Jensen, U., Stochastic Models in Reliability, Springer, 1998.

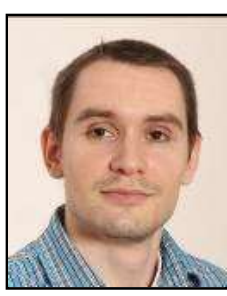

Ivan Palinkaš was born in Zrenjanin, Serbia, 11/15/1984. Information of education are listed below:

BSc studies in managing medical technical system, University of Novi Sad, Technical faculty "Mihajlo Pupin", Zrenjanin, Serbia, 2008.

MSc studies in industrial engineering, University of Novi Sad, Technical faculty "Mihajlo Pupin", Zrenjanin, Serbia, 2015.

Student on $\mathrm{PhD}$ studies in Engineering management/Industrial engineering.

$\mathrm{He}$ is currently working in Technical faculty "Mihajlo Pupin" in Zrenjanin, University of Novi Sad, as Teaching Assistant in field of Mechanical Engineering. $\mathrm{He}$ is the co-author of textbook "Tribology and lubrication", Zrenjanin, Serbia, Technical faculty "Mihajlo Pupin”, 2014. 